\title{
SPECIFICITY OF THE HUMAN INTESTINAL DISACCHARIDASES AND IMPLICATIONS FOR HEREDITARY DISACCHARIDE INTOLERANCE *
}

\author{
BY ARNE DAHLQVIST
}

(From the Department of Physiological Chemistry, University of Lund, Sweden)

(Submitted for publication June 27, 1961 ; accepted October 27, 1961)

The existence of several different $\alpha$-glucosidases has recently been demonstrated in extracts of pig intestinal mucosa (1-7). These enzymes have varying specificity for disaccharides with $\alpha$-D-glucopyranoside structure (e.g., maltose, sucrose, isomaltose, trehalose), and thus the intestinal hydrolysis of these sugars is caused by a more complicated enzyme mixture than had been previously believed $(8,9)$.

The $\beta$-glucosidase and $\beta$-galactosidase activities of extracts of pig intestinal mucosa, in contrast, seem to be exerted by one enzyme, intestinal lactase $(10,11)$.

It is not known whether the specificity of the human intestinal disaccharidases parallels that of the pig enzymes. This question is of clinical importance, however, since several cases of hereditary inability to digest certain disaccharides have been recently described, and are apparently caused by inherited deficiency of single intestinal disaccharidases (12-19).

Since the human intestinal content, obtained by a catheter during the digestion of a meal, contains essentially no disaccharidases $(20,21)$, this material cannot be used for the study of the specificity of these enzymes. Therefore homogenates have been prepared of human intestinal mucosa, obtained from pieces of small intestine cut out during surgical operations. These homogenates had powerful disaccharidase activities, and the specificity of the enzymes responsible for these activities has been studied by heat inactivation.

\section{MATERIALS AND METHODS}

Homogenates of human intestinal mucosa. Two samples were obtained, one from the distal part of the jejunum, and the other from the distal part of the ileum.

* This investigation was supported by grants from the Swedish Medical Research Council and the Royal Physiographic Society at Lund, Sweden.
1) Jejunal sample, from a 40 year old woman; resection of the middle part of the small intestine was indicated by an intestinal tumor. From an $8-\mathrm{cm}$ piece of normal intestine, located in the distal decimeters of the jejunum, $1.6 \mathrm{~g}$ of mucosa was scraped off with a glass slide. The mucosa was homogenized for 1 minute in an Ultra-Turrax homogenizer with $4.8 \mathrm{ml}$ of 0.9 per cent $\mathrm{NaCl}$, the tube being chilled with crushed ice during homogenization. After removal of nuclei and greater cell debris by centrifugation in an ordinary laboratory centrifuge (Wifug, rotor no. 103-30A, 4,000 rpm) for 10 minutes, the opalescent supernate, which contains the disaccharidases (22), was used for analysis. 2) Ileal sample, from a 26 year old woman suffering from chronic ulcerative colitis; reoperation of ileocecal anastomosis indicated by abdominal abscess. A $15-\mathrm{cm}$ piece of the distal part of the ileum was removed. The intestinal wall of this piece showed considerable induration, but the mucosa appeared macroscopically normal; $3.0 \mathrm{~g}$ of mucosa was obtained by scraping with a glass slide. The mucosa was homogenized as described above with $9.0 \mathrm{ml}$ of 0.9 per cent $\mathrm{NaCl}$.

Assay of disaccharidase activities was performed by the methods previously described $(23,24)$ using the Tris-glucose oxidase reagent (24). One unit of disaccharidase activity causes 5 per cent hydrolysis in $2.0 \mathrm{ml}$ of $0.028 \mathrm{M}$ substrate, which is equal to the formation of $1 \mathrm{mg}$ monosaccharide (23), in 60 minutes at $37^{\circ} \mathrm{C}$ and at optimum $\mathrm{pH}$.

Assay of polysaccharidase activities was done as previously described (25). One unit of amylase or dextranase activity catalyzes an increase in reducing power corresponding to $1 \mathrm{mg}$ of disaccharide (monohydrate) in 60 minutes at $37^{\circ} \mathrm{C}$, and may thus be compared with the unit for disaccharidase activity.

Assay of protein was performed by the method of Lowry, Rosebrough, Farr and Randall (26) with the modified reagent $B$ introduced by Eggstein and Kreutz (27). A standard curve was prepared with human serum albumin, kindly supplied by AB Kabi (Stockholm).

Heat inactivation. When a solution of an enzyme is heated at a sufficiently high temperature the enzyme is inactivated, following the kinetics of a first-order reaction. The temperature interval within which the velocity constant for the inactivation increases from zero (no measurable inactivation) to very high values (complete inactivation within a few minutes) is usually less than $10^{\circ}$. Since the different glycosidases present in extracts of pig 
intestinal mucosa have widely different sensitivities to heat, fractionated heat inactivation provided a useful method for the separation of these enzymes $(3,28,29)$.

The rate of the heat inactivation at a certain temperature is strongly dependent on the $\mathrm{pH}$ of the solution; thus an appropriate buffer must be added. It is also desirable to heat the enzyme solution to the desired inactivation temperature as quickly as possible and then to maintain this temperature within $\pm 0.1^{\circ}$ during the experiment. The enzyme solution which is to be inactivated (usually a volume of 5 to $10 \mathrm{ml}$ ) was therefore first immersed in a preheating bath that had a temperature $7^{\circ}$ to $8^{\circ}$ higher than the inactivation bath. During the preheating the tube was continously shaken, and the temperature of the enzyme solution was measured with a thermometer having $0.1^{\circ}$ gradations. At the moment the desired inactivation temperature was reached (under these conditions this occurred in less than $1 \mathrm{~min}$ ute) the tube was transferred to the inactivation bath; at the the same time a zero-time sample was taken for enzyme analysis and a stopwatch was started. Care was taken that the inactivation temperature was never exceeded during preheating. New samples for enzyme analysis $(0.5$ to $1 \mathrm{ml})$ were withdrawn at intervals, immediately blown down into tubes chilled with crushed ice, and so stored until analyzed.

The enzyme solutions for heat inactivation in the present case were prepared by mixing 1 vol of homogenate (the jejunal sample, which was strongest in disaccharidase activity, had first been diluted 1:2 with distilled water) with 4 vol of $0.0125 \mathrm{M}$ sodium phosphate buffer, $\mathrm{pH}$ 7.0.

Validity of separation by heat inactivation. The separation of two enzymatic activities, present in the same preparation, only on the basis of their different sensitivities to heat, does not conclusively prove that the two activities are manifestations of different enzyme proteins; heating the solution may affect activators or inhibitors, breaking single bonds within the enzyme molecule may alter the specificity of the enzyme, and so forth. Inversely, the parallel heat inactivation of two different enzymatic activities does not necessarily mean that these are caused by the same enzyme; two different enzymes may very well have similar heat inactivation properties. The results of heat inactivation experiments therefore must be compared with those of other separation methods, such as fractionation with different precipitants, electrophoresis, ion-exchange chromatography, and so on. By such methods the existence of several different disaccharidases in pig intestinal mucosa has been conclusively demonstrated and the specificity of the different enzymes elucidated $(3-7,10,28-30)$. In this study the results of the heat inactivation experiments agreed very well with those of the other methods. Furthermore, the heat inactivation analysis was found to be the most simple and accurate method for the analysis of the mixture of disaccharidases present in extracts of pig intestinal mucosa $(3,29)$.

The heat inactivation properties of disaccharidase preparations of human intestinal mucosa described in this paper indicate that the human intestine contains disaccharidases which are essentially similar to the corresponding enzymes of the pig, although some differences are found. The chromatographic separation of the pig enzymes succeeded only with the use of a special technique-mutual displacement chromatography (29)which demanded rather large amounts of enzyme material. The limited amount of enzyme available with human preparations prohibited separation experiments with this method. Chromatographic separation of the human disaccharidases will have to await the development of a suitable micromethod.

\section{RESULTS}

The homogenates had powerful disaccharidase activities. The relative rate of hydrolysis of different disaccharides was essentially the same as that reported earlier for preparations from the mucosa of the adult pig $(23,25)$, except that the relative isomaltase activity of the human preparations was stronger and the trehalase activity somewhat weaker than in the pig (Table I).

The lactase activity of the jejunal sample was strong, but this activity was practically absent in the ileal sample, indicating that lactase in the human is localized in the proximal part of the intestine as it is in the pig (25). This is also in accordance with the finding that lactose is absorbed in the proximal part of he human small intestine (21).

The cellobiase and gentiobiase activities in the two samples paralleled the lactase activity (Table I), indicating that also in the human intestine $\beta$-glucosides and $\beta$-galactosides may be hydrolyzed by a single enzyme $(10,11)$.

TABLE I

Carbohydrase activities of the homogenates of human small intestinal mucosa *

\begin{tabular}{lcc}
\hline $\begin{array}{c}\text { Carbohydrase } \\
\text { activity }\end{array}$ & $\begin{array}{c}\text { a) Jejunal } \\
\text { sample }\end{array}$ & $\begin{array}{c}\text { b) Ileal } \\
\text { sample }\end{array}$ \\
\hline Maltase (total) & \multicolumn{2}{c}{ units/g } \\
mucosa \\
Invertase & 948 & 292 \\
Isomaltase & 360 & 40 \\
Trehalase & 272 & 69 \\
Turanase & 31 & 17 \\
Palatinase & 74 & 23 \\
Lactase & 59 & 12 \\
Cellobiase & 412 & 3.2 \\
Gentiobiase & 78 & 0.6 \\
Amylase & 2.4 & 0.0 \\
Dextranase & 1,328 & 960 \\
& 32 & 8.8 \\
\hline
\end{tabular}

* Protein content: a) $82 \mathrm{mg}$, b) $92 \mathrm{mg} / \mathrm{g}$ tissue. 


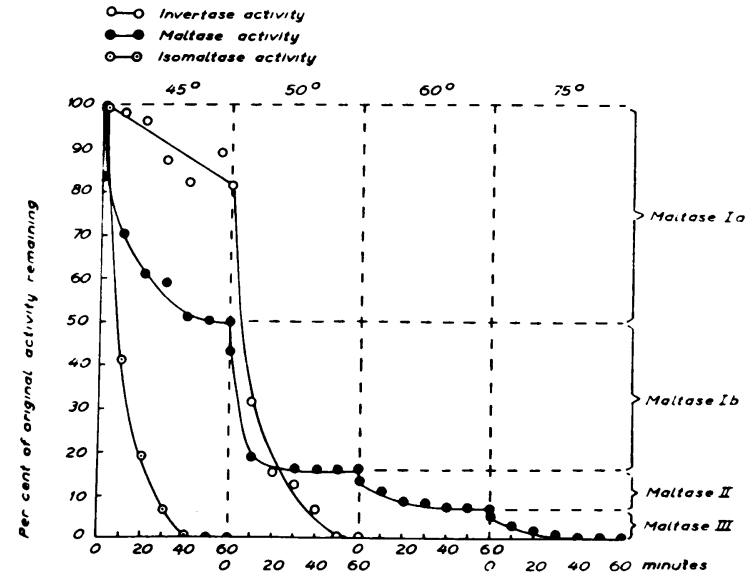

Fig. 1. Heat inactivation of the human intesTINAL $\alpha$-GLUCOSIDASES IN FOUR STEPS. The enzyme solution contained $2 \mathrm{mg}$ protein per $\mathrm{ml}$ in $0.01 \mathrm{M}$ sodium phosphate buffer, $\mathrm{pH}$ 7.0. The original disaccharidase activities (before heating) were: invertase 7.9, maltase (total) 21.4, and isomaltase $6.1 \mathrm{U}$ per $\mathrm{ml}$.

The amylase activity, in contrast to the disaccharidases, was weaker in the mucosal samples than in intestinal contents (21), in harmony with the conception that this enzyme is mainly secreted from the pancreas $(21,25)$. It cannot be stated whether the amylase present in the mucosal homogenates originates from the mucosa per se or from contaminating intestinal contents.

Dextranase which, like the disaccharidases, is located in the intestinal mucosa (25), had activity comparable with that in preparations from pig mucosa.

\section{Heat inactivation of the disaccharidases}

A. Maltase activity. The course of the heat inactivation of the maltase activity of the homogenates did not follow first-order kinetics, indicating that the maltase activity was caused by a mixture of several enzymes with different sensitivities to heat. By heating at temperatures increased stepwise, the maltase activity could be divided into four different fractions (maltase Ia, Ib, II, and III $^{1}$ ), in order of increasing resistance to heat (Figure 1). The fraction of the total maltase activity in the homogenates that was produced by each of these enzymes is seen in Table II. As

\footnotetext{
1 By analogy with the pig enzymes $(28,29)$, naming the two most heat-labile human maltase fractions Ia and Ib seems more consistent than calling the human maltase fractions I-IV.
}

concluded from their sensitivity to heat and their relation to the invertase activity, maltase Ib, II, and III in these samples correspond to maltase I, II, and III, respectively, in the pig intestinal mucosa $(3,4,29)$. Thus there exists in the human intestine one further enzyme with maltase activity, maltase Ia. This new enzyme was inactivated parallel with the isomaltase activity (Figure 1), which may indicate that the maltase Ia and the isomaltase activities are produced by the same enzyme, a hypothesis that, of course, needs further experimental proof. This hypothetical enzyme was responsible for about half of the total maltase activity in the preparations of human mucosa (Table II) and accounted for essentially all of the isomaltase activity of the preparations. About 15 to 20 per cent of the invertase activity also was inactivated during heating at $45^{\circ} \mathrm{C}$ for 60 minutes (Figure 1). The inactivation of this fraction of the invertase activity proceeded, however, more slowly than the inactivation of the maltase Ia and isomaltase activities, and thus there seems to be no reason to ascribe any measurable invertase activity to maltase Ia.

$B$. Invertase activity. The heat inactivation of invertase at all temperatures was in accordance with the kinetics of a first-order reaction, indicating that the human intestinal invertase activity, like that of the pig $(3,4,6,28)$, is caused by a single enzyme. The human maltase Ib activity was inactivated simultaneously with the invertase activity, and the invertase and maltase Ib activity is probably caused by one enzyme, which seems to have properties similar to the pig maltase I (invertase) (6). With this assumption the maltase/ invertase activity quotient for this enzyme was calculated to be 1.0, which may be compared with 0.7 for the pig enzyme (23).

$$
\text { TABLE_II }
$$

Fractions of the total maltase activity of the homogenates produced by each of the different maltases of human intestinal mucosa

\begin{tabular}{ccc}
\hline \hline Enzyme & $\begin{array}{c}\text { a) Jejunal } \\
\text { sample }\end{array}$ & $\begin{array}{c}\text { b) Ileal } \\
\text { sample }\end{array}$ \\
\hline & \multicolumn{2}{c}{ \%of total maltase } \\
Maltase Ia & 50 & 44 \\
Maltase Ib & 34 & 16 \\
Maltase II & 9 & 20 \\
Maltase III & 7 & 20 \\
\hline
\end{tabular}


C. Isomaltase activity. The isomaltase activity also seemed to be caused by a single enzyme in the human preparations, as concluded from the kinetics of the heat inactivation. Like the specific isomaltase in the pig (31), which in this species accounts for the major part of the isomaltase activity $(7,23)$, the human isomaltase was inactivated with the most heat-sensitive disaccharidase fraction (Figure 1). As concluded from the heat inactivation experiments, the human isomaltase and maltase Ia are caused by the same enzyme. If this is the case, there is a difference in specificity between the human and the pig isomaltase, for the specific isomaltase of the pig has no maltase activity $(3,7,31)$. The maltase/isomaltase activity quotient for the human enzyme was calculated to be 1.8 .

Although the specific isomaltase in the pig accounts for the major part of the isomaltase activity (23), the pig maltase II and maltase III also produce weak isomaltase activity, caused by these enzymes per se $(4,30)$. The present experiments do not rule out the possibility that the human maltase II and maltase III have isomaltase

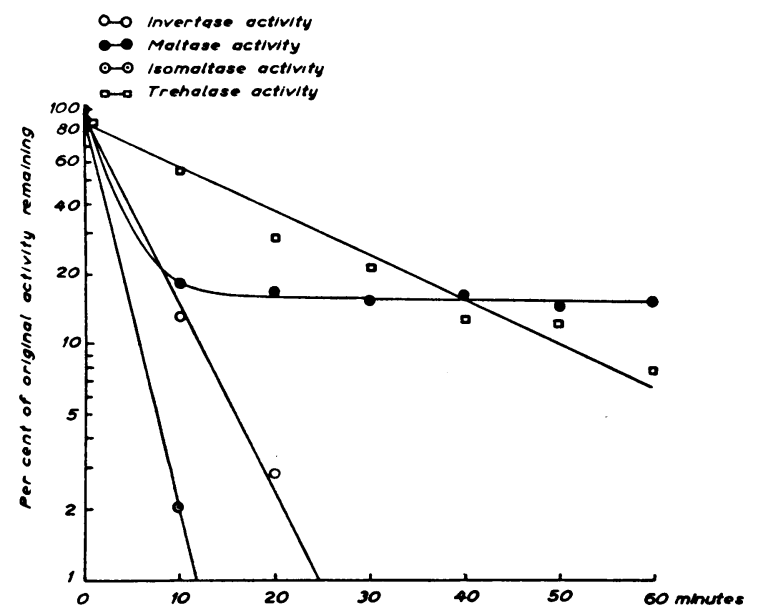

Fig. 2. Separation of trehalase from the other HUMAN INTESTINAL $\alpha$-GLUCOSIDASES BY HEATING AT $52^{\circ}$ C. The enzyme solution contained $2 \mathrm{mg}$ of protein per $\mathrm{ml}$ in $0.01 \mathrm{M}$ sodium phosphate buffer, $\mathrm{pH} 7.0$. The original disaccharidase activities were: invertase 7.9 , maltase (total) 21.4, isomaltase 6.1 , and trehalase, $0.5 \mathrm{U}$ per $\mathrm{ml}$. The trehalase activity decreases slowly, following the kinetics of a first-order reaction. It is thereby clearly distinguished from the isomaltase, invertase, maltase Ia, and maltase Ib activities, which are rapidly inactivated, and from the maltase II and maltase III activities which are not measurably affected.

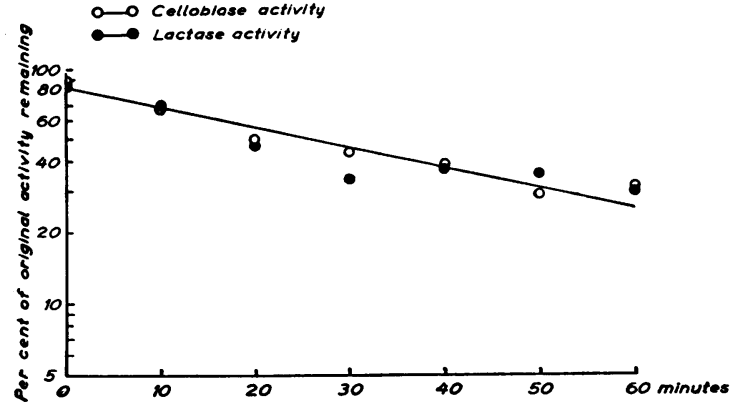

Fig. 3. Heat inactivation of the human intestiNAL CELLOBIASE ( $\beta$-GLUCOSIDASE) AND LACTASE ( $\beta$-GALACTOSIDASE) ACTIVITIES AT $50^{\circ} \mathrm{C}$. The enzyme solution contained $2 \mathrm{mg}$ of protein per $\mathrm{ml}$ in $0.01 \mathrm{M}$ sodium phosphate buffer, $\mathrm{pH}$ 7.0. Cellobiase activity 1.8, and lactase $7.5 \mathrm{U}$ per $\mathrm{ml}$. The cellobiase and lactase activites are inactivated slowly and parallel each other, indicating that these activities may be produced by a single enzyme.

activity comparable with that of the pig enzymes, although this activity would have been too weak to be detected.

D. Trehalase activity. The human trehalase activity seemed homogeneous in the heat inactivation experiments (Figure 2). At $52^{\circ} \mathrm{C}$ the trehalase activity was slowly inactivated, and thereby completely distinguished from the isomaltase, invertase, maltase Ia, and maltase Ib activities, which were rapidly inactivated; and also from the maltase II and maltase III activities, which were not measurably affected (Figure 2). As in the pig (5), therefore, the trehalase in the human intestine seems to be a specific enzyme, distinguished from the other human intestinal $\alpha$-glucosidases.

E. Cellobiase and lactase activity. Both cellobiase and lactase activities were inactivated in accordance with the kinetics of a first-order reaction, and the inactivation of these activities ran parallel (Figure 3). With the human enzymes it was thus indicated that a single intestinal disaccharidase may hydrolyze both $\beta$-glucosides and $\beta$-galactosides, in accordance with previous results with the pig enzyme $(10,11)$.

\section{Comparison of the human intestinal disaccharidases with those of the pig}

The heat inactivation experiments indicate the existence of at least six different disaccharidases in the human small intestinal mucosa (Table III). The main difference from the pig enzymes $(3,10)$ seems to be that the human isomaltase probably 
TABLE III

Specificity of human intestinal disaccharidases and their quantitative importance for the hydrolysis of different disaccharides as concluded from heat inactivation experiments

\begin{tabular}{llc}
\hline \hline \multicolumn{1}{c}{ Enzyme } & Substrate & $\begin{array}{c}\text { \% of total activity } \\
\text { against each } \\
\text { substrate }\end{array}$ \\
\hline Isomaltase $=$ maltase Ia & $\begin{array}{l}\text { Isomaltose } \\
\text { Maltose }\end{array}$ & $\begin{array}{r}100 \\
50\end{array}$ \\
Invertase $=$ maltase Ib & $\left\{\begin{array}{l}\text { Sucrose } \\
\text { Maltose }\end{array}\right.$ & 100 \\
Maltase II & Maltose & 15 \\
Maltase III & Maltose & 10 \\
Trehalase & Trehalose & 100 \\
Lactase & Lactose & 100 \\
& Cellobiose & 100 \\
\hline
\end{tabular}

has considerable maltase activity, which the corresponding pig enzyme (specific isomaltase) has not $(7,31))$. As a consequence, there exist in the human intestine not fewer than four different enzymes with maltase activity, as compared with three in the pig.

There appears to be a developmental difference in the intestinal disaccharidases of the two species. The intestinal lactase activity is strong at birth in both species $(11,32)$. In the newborn pig, however, the intestinal $\alpha$-glucosidases are weak or absent, and these enzymes develop gradually during growth $(11,33,34)$. As a consequence, the newborn pig cannot utilize dietary sucrose or maltose (35). The normal child, however, is able to utilize sucrose or maltose equally as well as lactose (17-19), and invertase has been demonstrated in the intestine of the newborn child and the human fetus as early as the third month of intrauterine life (36). The intestinal $\alpha$-glucosidases of the human therefore appear to be already well developed at birth.

\section{DISCUSSION}

Implications of disaccharidase specificity for hereditary disaccharide intolerance

Several cases have been recently described of inherited inability to utilize one or another disaccharide (12-19). These patients suffer from malnutrition and usually develop diarrhea on peroral ingestion of the disaccharide. No rise in blood sugar is noted in these patients on peroral adminis- tration of the disaccharide they cannot utilize, but the administration of the corresponding monosaccharides or other disaccharides is followed by the normal blood sugar response. In some cases the unhydrolyzed disaccharide has been demonstrated in the urine or in the feces $(12,14-16,18)$. Loss of weight, flatulence, abdominal pain, increased excretion of volatile fatty acids (formed by intestinal bacteria), vomiting, and renal acidosis have been reported, and the condition may be fatal. If the poorly tolerated disaccharide is excluded from the diet and replaced by monosaccharides or other utilizable carbohydrates, the symptoms disappear. Although enzymatic analysis of the intestinal mucosa of these patients has hitherto not been performed, there seems to be sufficient evidence for the conception that the disease is caused by inherited deficiency of single intestinal disaccharidases.

The enzyme deficiency is apparently compensated after the first years of life, but the mechanism for this is unknown (18).

A. Disaccharide intolerance to be expected from deficiency of the different disaccharidases. Some of the intestinal disaccharidases act on more than one kind of substrate, and certain substrates are hydrolyzed by more than one intestinal enzyme. With the assumptions made above about the specificity of the human intestinal disaccharidases, certain predictions can be made about the disaccharidase intolerance to be expected from the deficiency of each of the different intestinal disaccharidases. Sucrose intolerance can occur by itself, without simultaneous intolerance for other disaccharides. Although the human intestinal invertase seems to be identical with maltase Ib, and consequently the absence of invertase will entail the absence also of the maltase Ib activity, the other maltases will be strong enough to ensure sufficient hydrolysis of maltose. Isomaltose intolerance for corresponding reasons also can occur as an isolated defect. Maltose intolerance cannot be caused by a single enzyme deficiency but demands the simultaneous lack of four different enzymes. Maltose intolerance will probably always be accompanied by intolerance for sucrose and isomaltose. Trehalose intolerance can occur separately, since intestinal trehalase is a specific enzyme without action on the other disaccharides. Lactose intolerance can occur without simultaneous deficiency in $\alpha$-glu- 
cosidases, but will probably always be accompanied by cellobiose intolerance.

B. Nutritional importance of the different disaccharides. The clinical consequences of intolerance for (inability to utilize) a disaccharide will be dependent on the amount of this disaccharide present in the diet. Sucrose intolerance will give marked symptoms when the child begins to get a mixed diet, since sucrose is one of the major carbohydrate components in our food (37). In artificial feeding of the newborn child sucrose is commonly added, and may thus initiate the symptoms in an invertase-deficient infant. Both maltose and isomaltose intolerance will interfere with the utilization of dietary starch $(1,2)$, which is the main source for these disaccharides and related oligosaccharides, formed by the action of amylase. Trehalose intolerance will give scarcely any clinical symptoms at all at any age, since trehalose is present only in very small amounts in our food (37). This seems especially remarkable, since intestinal trehalase has very marked specificity for its substrate (5). Lactose intolerance will cause severe malnutrition in the newborn child, especially if the child is breast fed, since lactose constitutes practically all of the carbohydrate in milk, and accounts for nearly 50 per cent of its caloric value. Cellobiose intolerance is associated with lactase deficiency. The cellobiase deficiency as such will not, however, be of any clinical importance, since cellobiose is not present in our diet in any significant amount (37), and we possess no cellulase hydrolyzing cellulose to disaccharide.

C. Comparison of theory with cases of disaccharide intolerance described. Prader, Auricchio and Mürset (18) have described five patients with sucrose intolerance, all of whom had normal tolerance for maltose and lactose. These patients probably suffered from isolated deficiency of intestinal invertase. Weijers and associates $(17,19)$ described three patients with sucrose intolerance. Two of these patients, like those of Prader and coworkers, had normal tolerance for maltose and lactose, while the third showed intolerance also for maltose. The latter patient thus may be deficient in all the four different intestinal disaccharidases responsible for maltase activity (isomaltase $=$ maltase $\mathrm{Ia}$, invertase $=$ maltase $\mathrm{Ib}$, maltase II and maltase III). The tolerance for lactose was normal. This patient seems to be the only case so far known in whom more than one disaccharidase was shown to be absent. In this patient isomaltose intolerance would also be expected, but no test with this disaccharide was described. In fact, no case of intolerance for isomaltose has so far been described, although this defect can be expected to cause clinical symptoms (decreased ability to utilize starch).

Trehalose intolerance has never been described, and as an isolated defect will probably not cause clinical symptoms.

Lactose intolerance, which was first described by Durand (12), has hitherto been described in 11 patients $(12-16)^{2}$. In several cases this defect ran a fatal course $(12,14-16)$, reflecting the nutritional importance of lactose for the young child. In no case has it been stated that cellobiose intolerance is involved, as would be expected from the specificity studies. Sucrose, maltose, and starch have been tolerated by these patients (13).

The cases of disaccharide intolerance described above seem, with one exception, to have been caused by deficiency in a single intestinal disaccharidase. The findings concerning the specificity of the human intestinal disaccharidases agree well with the intolerance observed in these patients, so far as they have been investigated. In further work the possibility of isolated isomaltase deficiency has to be kept in mind as a possible cause of failure in the utilization of starch.

\section{SUMMARY}

Human intestinal mucosa homogenates hydrolyze a number of different disaccharides. Heat inactivation of the homogenates at varying temperatures in $0.01 \mathrm{M}$ sodium phosphate buffer, $\mathrm{pH}$ 7.0, has indicated that these disaccharidase activities are accounted for by a mixture of at least six separate enzymes-namely, five different $\alpha$-glucosidases, four of which have maltase activity, and lactase, which hydrolyzes both $\beta$-glucosides and $\beta$-galactosides. The $\alpha$-glucosidases separated are : maltase Ia ( = isomaltase), maltase Ib (= invertase), maltase II, maltase III, and trehalase.

Hereditary deficiency of single intestinal disaccharidases is known to appear in children. From

2 Weijers, van de Kamer, Dicke and Ijsseling (19) have observed five further cases of this defect, which have not yet been described in detail. 
the specificity of the human intestinal disaccharidases, it may be expected that intolerance for isomaltose, sucrose, or trehalose can appear as an isolated defect. Lactose intolerance will probably always be associated with cellobiose intolerance; and maltose intolerance, which demands the simultaneous absence of four separate enzymes, will probably always be accompanied by intolerance for sucrose and isomaltose.

As far as the disaccharidase-deficient patients described in the literature have been examined, their defects accord with this theory.

\section{ACKNOWLEDGMENT}

Grateful acknowledgment is made to Dr. Göran Lundh for supplying the samples of human intestine; Miss Alice Hansson and Miss Birgitta Andersson are thanked for skillful technical assistance.

\section{REFERENCES}

1. Larner, J., and McNickle, C. M. Gastrointestinal digestion of starch. I. The action of oligo-1,6-glucosidase on branched saccharides. J. biol. Chem. $1955,215,723$.

2. Larner, J., and Gillespie, R. E. Gastrointestinal digestion of starch. II. Properties of the intestinal carbohydrases. J. biol. Chem. 1956, 223, 709.

3. Dahlqvist, A. Hog intestinal $\alpha$-glucosidases. Solubilization, separation and characterization. Dissertation, Univ. of Lund, 1960.

4. Dahlqvist, A. Characterization of three different hog intestinal maltases. Acta chem scand. 1960, 14, 1 .

5. Dahlquist, A. Characterization of hog intestinal trehalase. Acta chem. scand. 1960, 14, 9.

6. Dahlqvist, A. Characterization of hog intestinal invertase as a glucosido-invertase. III. Specificity of purified invertase. Acta chem. scand. 1960, 14, 63.

7. Dahlqvist, A. Hog intestinal isomaltase activity. Acta chem. scand. 1960, 14, 72.

8. Weidenhagen, R. Spezifität und Wirkungsmekanismus der Carbohydrasen. Ergebn. Enzymforsch. 1932, 1, 168.

9. Gottschalk, A. $\alpha$-D-Glucosidases in The Enzymes, J. B. Sumner and K. Myrbäck. Eds. New York, Academic Press, 1950, vol. I, p. 551.

10. Dahlqvist, A. Pig intestinal $\beta$-glucosidase activities. I. Relation to $\beta$-galactosidase (lactase). Biochim. biophys. Acta 1961, 50, 55.

11. Dahlqvist, A. Intestinal carbohydrases of a newborn pig. Nature (Lond.) 1961, 190, 31.

12. Durand, P. Lattosuria idiopatica in una paziente con diarrea cronica ed acidosi. Minerva pediat. (Tôrino) 1958, 10, 706.
13. Holzel, A., Schwarz, V., and Sutcliffe, K. W. Defective lactose absorption causing malnutrition in infancy. Lancet 1959, 1, 1126.

14. Darling, S., Mortensen, O., and Søndergaard, G. Lactosuria and aminoaciduria in infancy. A new inborn error of metabolism? Acta paediat. (Uppsala) 1960, 49, 281.

15. Durand, $P$. Intolérance au lactose. Insuffisante hydrolyse intestinale du lactose. Pédiatrie 1960, 15, 407.

16. Jeune, M., Charrat, A., Cotte, J., Fournier, P., and Hermier, M. Sur un cas de lactosurie congénitale. Pédiatrie 1960, 15, 411.

17. Weijers, H. A., van de Kamer, J. H., Mossel, D. A. A., and Dicke, W. K. Diarrhoea caused by deficiency of sugar-splitting enzymes. Lancet 1960, 2, 296.

18. Prader, A., Auricchio, S., and Mürset, G. Durchfallinfolge hereditären Mangels an intestinaler Saccharaseaktivität (Saccharoseintoleranz). Schweiz. med. Wschr. 1961, 91, 465.

19. Weijers, H. A., van de Kamer, J. H., Dicke, W. K., and Ijsseling, J. Diarrhoea caused by deficiency of sugar splitting enzymes. I. Acta paediat. (Uppsala) $1961,50,55$.

20. Borgström, B., Dahlqvist, A., Lundh, G., and Sjövall, $\mathrm{J}$. Studies of intestinal digestion and absorption in the human. J. clin. Invest. 1957, 36, 1521.

21. Dahlqvist, A., and Borgström, B. Digestion and absorption of disaccharides in man. Biochem. $\mathrm{J}$. 1961, 81, 411.

22. Borgström, B., and Dahlqvist, A. Cellular localization, solubilization and separation of intestinal glycosidases. Acta chem. scand. 1958, 12, 1997.

23. Dahlqvist, A. "Substrate inhibition" of intestinal glycosidases. Acta chem. scand. 1960, 14, 1797.

24. Dahlquist, A. Determination of maltase and isomaltase activities with a glucose-oxidase reagent. Biochem. J. 1961, 80, 547.

25. Dahlqvist, A. The location of carbohydrases in the digestive tract of the pig. Biochem. J. 1961, 78, 282.

26. Lowry, O. H., Rosebrough, N. J., Farr, A. L., and Randall, R. J. Protein measurement with the Folin phenol reagent. J. biol. Chem. 1951, 193, 265.

27. Eggstein, M., and Kreutz, F. H. Vergleichende Untersuchungen zur quantitativen Eiweissbestimmung im Liquor und eiweissarmen Lösungen. Klin. Wschr. 1955, 33, 879.

28. Dahlquist, A. Studies on the heat inactivation of intestinal invertase, maltase and trehalase. Acta chem. scand. 1959, 13, 945.

29. Dahlqvist, A. The separation of intestinal invertase and three different intestinal maltases on TEAEcellulose by gradient elution, frontal analysis, and mutual displacement chromatography. Acta chem. scand. 1959, 13, 1817.

30. Dahlqvist, A. Specificity of a purified hog int/stinal maltase fraction. Competitive inhibition of realtase 
activity by other substrates. Acta chem. scand. 1959, 13, 2156.

31. Dahlqvist, A. Hydrolysis of palatinose (isomaltulose) by pig intestinal glycosidases. Acta chem. scand. 1961, 15, 808.

32. Tachibana, T. Physiological investigation of fetus. IX. Supplementary research of ferments in digestive organs: Lactase in intestinal canal. Jap. J. Obstet. Gynec. 1929, 12, 100.

33. Bailey, C. B., Kitts, W. D., and Wood, A. J. The development of the digestive enzyme system of the pig during its pre-weaning phase of growth. B. Intestinal lactase, sucrase and maltase, Canad. J. agric. Sci. 1956, 36, 51.
34. Walker, D. M. The development of the digestive system of the young animal. II. Carbohydrase enzyme development in the young pig. J. agric. Sci. 1959, 52, 357.

35. Becker, D. E., Ullrey, D. E., Terrill, S. E., and Notzold, R. A. Failure of the newborn pig to utilize dietary sucrose. Science 1954, 120, 345.

36. Tachibana, T. Physiological investigation of fetus. VIII. Supplementary research of ferments in digestive organs: Invertase in intestinal canal. Jap. J. Obstet. Gynec. 1929, 12, 40.

37. Day, H. G., and Pigman, W. W. Carbohydrates in nutrition in The Carbohydrates, W. W. Pigman, Ed. New York, Academic Press, 1957, p. 779. 